\title{
Portraits, Likenesses, Composites? Facial Difference in Forensic Art \\ Kathryn Smith
}

\section{Introduction}

Reflecting on recognition, Ludwig Wittgenstein commented:

It is easy to have a false picture of the process called 'recognizing'; as if recognizing always consisted in comparing two impressions with one another. It is as if I carried a picture of an object with me and used it to perform an identification of an object as the one represented by the picture...And it is not so much as if I were comparing the object with the picture beside it, but as if the object coincided with the picture. I see only one thing not two. ${ }^{1}$

A crime is witnessed, a suspect is sought. A witness is interviewed, ideally with 48 hours but usually much longer after the event. They may be traumatized. The structured conversation between witness and forensic artist produces an image, usually rendered as a greyscale image of limited tonal range that has a loose association with photo-realism. Sometimes these images are very detailed, demonstrating skilled draughtsmanship and embodying a distinct affect. More often they resemble a barely believable character from an early-generation video game, their facial parts floating on a basic head shape, sometimes without a neck but perhaps wearing a hat or glasses; whatever the witness regarded as salient and specific details that distinguished the individual. These are the images that you might see flashed up on the evening news, or pinned to the wall of your neighbourhood convenience store or police station.

The police composite sketch is arguably the most fundamental example of forensic art, with its origins in the most primary method of visual representation: drawing. Even though contemporary composites are digital images, produced using computer software, the 'sketch' descriptor often

\footnotetext{
${ }^{1}$ Wittgenstein cited in M. Podro, Depiction (New Haven: Yale UP, 1998), 180, note 1
} 
persists. These images possess considerable cultural cachet, an iconic visual shorthand for 'criminal investigation'. Based on verbal descriptions drawn from memory deriving from highly contingent events, composites are by definition unique and precarious forensic objects, representing an epistemological paradox in their definition as simultaneous 'artistic impression' and 'pictorial statement'. As artefacts of an eyewitness account, they lend support to an investigation yet should not be considered hard evidence, although the eyewitness account itself carries significant evidentiary weight. Contingent, contested and controversial, despite decades of operational use only in recent years has the field of cognitive psychology begun to fully understand and address the conditions that affect recognition rates both positively and negatively. ${ }^{2}$

This paper advances an interpretation of 'facial difference' by transposing this idea onto the theory and practice of forensic art, in order to explore variation in facial depictions produced by and for the forensic context, with specific reference to the police composite. Forensic art describes a range of practices which produces facial images to aid processes of human identification. The quantification and reproducibility of facial likeness has indisputable forensic value. A core practice within human identification - police have long employed artists or officers with artistic ability to assist with aspects of criminal investigations. this forensic value is produced via its claims to scientific truth, created via scientific experimentation and validation in which repeatability is a core principle. Intended to produce a positive identification of a specific individual, forensic facial depictions are a form of visual intelligence and in theory, should not be considered evidence that 'proves' identification. This makes sense, given the often apparent difference between the published facial image and the person eventually identified. Others exhibit uncanny similarities to their intended target.

${ }^{2}$ See The Innocence Project (https://www.innocenceproject.org/) which is committed to overturning wrongful convictions based on eyewitness identification. 
As an interdisciplinary practitioner working across both contemporary art and forensic contexts, I have an enduring interest in how contemporary art (and culture at large) is increasingly informed by forensic practices. This chapter represents some first steps in the context of a broader project that develops a theory of forensic art written from an interdisciplinary, practitioner perspective, in which I attend to ways in which knowledge transfers from one area of praxis to the other, and how these respective concerns are shaped in turn. In this transdisciplinary space, methods and ideals conventionally associated with laboratory research (empiricism, quantitative assessment, objectivity) are always in conversation with the subjective contingencies and desires, as well as critical rigour (formal analysis, aesthetic evaluation and interpretation) of the visual arts studio.

The human face is a highly complex organ, the anatomy, function and appearance of which is the domain of a host of individual disciplinary or specialist fields, from human identification and biometrics; maxillo-facial, reconstructive and aesthetic surgery; neuroscience and cognitive psychology; computer vision, machine learning and artificial intelligence engineers; animators, game-designers and of course, visual artists. Representations of the face exist as some of oldest examples of visual material culture (consider the Jericho skulls or Fayyum portraits), and the portrait remains an enduring genre in figurative art forms, especially photography. Yet manual and mechanical techniques still embody equivocal attitudes to mimetic truth, with painting and sculpture considered inherently subjective forms of visual representation, and mechanical processes continuing to enjoy a more intimate relationship to scientific objectivity and of course, reproductive efficiency. As a 'visual record', photography became the dominant mode of truthful and accurate visual representation, from bureaucratic structures to creative endeavours, clinical imaging and the domestic realm, theorized with reference to its 'indexicality' in the semiotic sense. That which it depicts once existed in the world, in front of a camera's lens. ${ }^{3}$ It is widely

\footnotetext{
${ }^{3}$ I am particularly interested in recent projects aimed at recuperating the analogous rather than indexical nature of photography's verisimilitude or those which make a powerful case for the indexicality of the digital photographic image: Roland Barthes, Camera Lucida: Reflections on Photography (New York: Hill and Wang, 1981); Susan Sontag, Regarding the Pain of Others (London: Hamish Hamilton, 2003); K. Silverman, The Miracle of Analogy: Or the History of Photography, Part 1 (California: Stanford University Press, 2015); Kris Paulsen, 'The Index and the Interface', Representations, vol. 122, no. 1 (Spring 2013), pp.83-109; Errol Morris, Believing
} 
accepted that a portrait is not simply an indexical or analogical likeness of a real face, but gathers into its representational ambit a host of conceptual ideas - social status, for example - that attach to the face to create a persona. Entering the virtual and AI realm, robotics and gaming practitioners contend with the 'uncanny valley', the perceptual-psychological interstice first described as Bukimi no Tani Genshō by Masahiro Mori (1970) as the almost abject process by which we elect whether to suspend our disbelief in the face of humanoid entities (automaton, dolls and social robots). ${ }^{4}$

When presented with the problem of reproducing likeness or similarity, which is by extension a question of understanding difference, the scientific imperative is to quantify. Knowledge is synonymous with particular kinds of measurement. Where faces are concerned, the scientific tendency is to act like a land surveyor, plotting facial landmarks and measuring the distances between them, comparing spatial configurations with the shape of individual features, interpolating missing data, noting deviations and ultimately producing geometrically elaborate 2D and 3D topographies of the face. Appearance becomes a technology of individuality and difference.

But what of the less tangible data that faces give us? Assuming the face is visible (and not covered for religious or other reasons), and we are able to see it (blindness and prosopagnosia excepted), its complex topography is what we attempt to read, albeit in different ways, when we are meeting someone for the first time. Following Levinas, the face as a space of empathetic encounter echoes the focus of our attention in our early infancy as we learned the fundamentals

is Seeing (New York: Penguin, 2014) and see Jason Bate's chapter in this volume for the telescoping of past with present.

${ }^{4}$ M. Mori, 'The uncanny valley (trans. K. F. MacDorman and Norri Kageki)', IEEE Robotics and Automation, 19.2 (2012): 98-100. (Original work published in 1970). doi:10.1109/MRA.2012.2192811. Online: http://spectrum.ieee.org/automaton/robotics/humanoids/the-uncanny-valley. Accessed 7 September 2016. A. Tinwell, The Uncanny Valley In Games and Animation (Boca Raton: CRC Press, 2015), extends this into the sophisticated CGI creations of gaming and animation, and interrogates that affective quality of such bodies and faces, offering a productive application of developmental psychologist Edward Tronick's Still-Face Effect: E. Z. Tronick, 'Things Still To Be Done on the Still-Face Effect', Infancy, 4.4 (2003): 475-482. 
of reciprocal communication. Recognition, Michael Podro reminds us, is 'the most basic relation we have to the world. ${ }^{5}$

The innumerable permutations of the face's mechanical and expressive movements etches their effects on our appearance over time. We can probably recognize someone we know well even if they completely change their hairstyle, or grow or shave their facial hair, or gain or lose a great deal of weight, but perhaps not? Making decisions about these factors, individually and in relation to one another, in terms of featural specificity as well as the holistic gestalt of a face, is what is required when we are forced to rely on a facial image to identify or locate someone in the absence of the accepted scientific methods - fingerprinting or DNA. (It may not be possible to extract a DNA sample from a set of human remains due to their condition. A DNA sample is only useful if there is a matching sample recorded and stored on a database for comparison, or if leads produce a family member who agrees to their DNA being taken for comparative purposes.)

The range of recognised forensic facial depiction methods used to promote identification of the living, missing or the unidentified dead are, at their most basic, either two- or three-dimensional representations of a particular human face, produced with direct or indirect reference to either material (skeletal) remains and related written/visual case documentation, or visual documentation of the person concerned. In the case of eye-witness composites, the primary reference material is at least one memory-derived verbal description. Techniques range from the hand-drawn or sculpted to hybrid manual-digital techniques, digital compositing and fully computer-automated systems.

\footnotetext{
${ }^{5}$ Podro, Depiction, Preface, n.p.; E. Levinas, 'Exteriority and The Face', in id., Totality and Infinity (The Hague/Boston/London: Martinus Nijhoff Publishers, 1979); id., 'The Face' in Ethics and Infinity: Conversations with Philippe Nemo (Pittsburgh: Duquesne University Press, 1985).
} 
The other most 'visible' expression of forensic art outside of the police sketch, are faces produced from skulls, a method for which the most robust scientific techniques exist. ${ }^{6}$ Less visible techniques are post-mortem depiction and age progression, which rely on a combination of skills required by both skull-based reconstruction and memory-derived composites. Postmortem depiction uses either drawing or digital photo-based compositing techniques (or a combination thereof) to sanitize photographic images of the unidentified dead to create publishable images, informed by a knowledge of post-mortem facial changes as a result of trauma or decomposition. Likewise, age progressions may be produced as sketches or more commonly, as digital photographic composites to produce impressions of what a missing child or adult (victim or fugitive) might look like years after their original disappearance. With the latter, the question of whether the individual is alive or dead must also remain open. Such images may be a lifeline for confused or bereaved families who have lost loved ones; we invest them with an enormous responsibility which they may fulfil if they are seen by the right person, even if they do not appear to achieve perfect verisimilitude with the target face.

Despite established data for predicting and depicting faces from skulls, marked differences in results are often seen in reconstructions of the same individual. Why does this happen? Is it an artefact of poorly applied scientific method or inadequate artistic skills, or both? Suspect composites show similar (even amplified) effects, but being derived from verbal description and memory, we should anticipate a far more fluid set of variables to be present.

It could be argued that reconstructions from the skull and composites are distinct processes, requiring different skill-sets, so why would it make sense to draw this comparison at the outset? Because of their operational function to track down active criminals, and the fact that eyewitness

\footnotetext{
${ }^{6}$ Due in large part to media exposure via television shows like BBC's 'History Cold Case' (2010-2011) and any number of forensic procedural dramas. For an illustrated history of how this method has developed scientifically and artistically, see the virtual exhibition 'The Evolution of Facial Depiction from Human Remains', curated by Face Lab (LJMU) for the Arts \& Humanities Research Council (UK) website. Online at http://www.ahrc.ac.uk/research/readwatchlisten/imagegallery/facialdepiction/. Accessed 19 September 2017.
} 
identification holds significant legal weight, composites have been given the lion's share of research attention in the area of face perception/cognition. These processes are embedded in their construction via eyewitness recall, in both linguistic and visual terms. Seen differently, considering the composite allows us to spend time with the face as both imaginative and recollected object. The composite is a specific kind of image, one produced from language, and one which language may further mobilize as an evidentiary object. Composites tend to depict suspects, which signify an immediacy that depictions of victims do not possess in quite the same way. An urgency is certainly present in victim images - it is a legal imperative to identify the dead and certainly an ethical one to locate the missing - but such depictions denote a vulnerable subject (loss of agency) whereas suspect images connote potential threat.

We could set out their differences according to simple differences: reconstructions from the skull are intended to identify victims and composites, perpetrators; in other words, the former serves the dead and the latter targets the (presumed) living. The former uses material things - human remains and associated objects - and the latter relies on more immaterial traces and expressions of memory and language. They are informed by different research areas, with anatomy and pathology informing facial reconstruction methodology and cognitive psychology driving eyewitness interviewing and identification techniques and their products. Operationally, these identification tasks are usually undertaken by different units within law enforcement agencies, although different countries adopt different approaches.

Both areas of practice certainly benefit from specific consideration of their respective functions, techniques and challenges. But imagined as a Venn diagram, the space in which they intersect is a central, core function of both endeavours: an understanding of how such images may be received by the communities that will ultimately allow them to do the work of depiction. How facially literate are we? Do we understand how these images are read and interpreted, in other words, how they are likely to be processed both cognitively and culturally? Are we, broadly speaking, visually literate when it comes to forensic facial depictions? 
The paradox between resemblance and recognition - that accuracy and likeness may not correlate as closely as we imagine they should - is the enduring conundrum of this work, and describes what animates my interest at a primary level. What might represent an artistic and aesthetic failure - poor anatomical accuracy or clumsy sketching, weak sculptural or Photoshop skills - may still be a forensic success if the depiction possesses sufficient gestalt to spark recognition. Visually different faces can be recognized as sufficiently similar to - if not precisely the same as - a missing loved one. Notwithstanding the practical fact of the image needing to be seen by the right person, the depiction may still be recognized, producing leads and - hopefully a scientifically-acceptable positive confirmation of biological identity (DNA and fingerprinting).

\section{Structure}

With reference to an interdisciplinary body of literature and practice-based experience (lab and field studies, criminal cases and recent contemporary art), this chapter explores the visual intelligence of forensic facial depictions, and the ways in which ideas about the face vary across the (often reluctantly) complementary practices of science and art. I consider these questions in relation to forensic art more broadly, its relationship to portraiture and concepts of accuracy and likeness by considering how the forensic composite is influencing the work of contemporary artists. Looking at forensic art 'awry' in this way (to borrow Slavoj Žižek's phrase), foregrounds the related but distinct ideas of 'identity' and 'identification', which inevitably entails a mention of the future of facial composites as bio-data models, and what the social, political and cultural implications of these new technologies and practices might be. ${ }^{7}$

I begin with a discussion of concepts of the face within forensic and visual art, exploring the languages we use to mobilize the face as a cultural and philosophical object and agent, from its ontology to its representational vocabulary. The discussion then moves to focus in on the

${ }^{7}$ Slavoj Žižek, Looking Awry: an Introduction to Jacques Lacan through Popular Culture (Cambridge, MA: MIT Press, 1991); H. Aldersley-Williams, K. Arnold, M. Gordon, N. Kotsopulos, J. Peto and C. Wilkinson, eds, Identity and Identification (London: Black Dog Publishing, 2009). 
composite, its functions and limits, and how this visual object has been used within cognitive psychology and computer vision research to develop knowledge about face perception.

Finally, the point about 'accuracy' is most clearly made where more than one reconstruction exists of a single, known individual. This principle guides my selection of examples, all of which explore correlations between multiple depictions, but also encompass the 'difference' in my title. The logic of the permutation is embedded in the ways in which composites are produced, and in turn how they have been studied within cognitive psychology, from the question of what to do with multiple witnesses to a single event, to the fact that caricatures in different visual styles can still be recognized as a certain person. The paradox animating the relationship between resemblance and recognition is extended by the idea that 'sketchy', 'incomplete' or cursorily drawn details, as well as distortion, can correct perceptual errors, and deliver a more convincing likeness than an image that attempts to slavishly mimic every detail of a face.

I conclude with a consideration of how concepts within visual art pertain to the (forensic) facial image, and in turn, how composites construct particular kinds of subjects. Considering time and language as significant contributing factors to their particular materiality, I understand composites as embodying the 'fugitive', in both literal and figurative terms. The uncanny spectres of faces created from pure data, including DNA, provide a further opportunity to consider whether, in the near future (or perhaps it is a moment we are already inhabiting?) notions of identification will float free of the facial image, and when, if ever, safety and security agencies and industries will liberate the face from their biometric-orientated, technophilic desires.

\section{Thinking through forensic art}

The very phrase 'forensic art' links two words with very different implications, intentions and practices, appearing to embody a paradoxical conjoining of applied science on the one hand, and 
creative interpretation and invention on the other. ${ }^{8}$ The scientific literature, particularly that focusing on accuracy studies (the relationship between likeness and repeatability) in facial reconstruction from the skull for example, ${ }^{9}$ has attracted a range of critique from so-called 'hard' scientists, with one even going so far as to dismiss the very notion of 'scientific art' as 'bizarre' ${ }^{10}$ Of course, this is historically and practically nonsensical. One only needs to cast the briefest glance at the rich and documented history of Western visual culture, from the Renaissance onwards, to find numerous examples of visual depiction - illustration, art, design, call it what you will - in the service of science, and artistic techniques that have scientific principles at their base, such as mathematical equations to achieve perspectival illusionism. A dismissive attitude towards the knowledge-producing potential of art also betrays a dangerously narrow view of what constitutes the 'scientific', which cannot be reduced to the purely quantitative. Art and science have more in common than not: both are informed by theory, driven by method, prompted by concept (innovative or not), executed by technique (skilled or not), and influenced by technology. ${ }^{11}$

Conventionally speaking, 'forensic art' is closely associated with facial images, reproduced with reference to human remains, testimony or visual documentation, although nomenclature within law enforcement may be confusing. The term 'forensic reconstruction' might be an operational term referring to spatial, rather than facial, visualization, as well as the production of

\footnotetext{
${ }^{8}$ C. M. Wilkinson, 'A review of forensic art', Research and Reports in Forensic Medical Science 5 (2015): 17-24.

${ }^{9}$ E.g. W. D. Haglund and D. T. Reay, 'Use of Facial Approximation Techniques in Identification of Green River Serial Murder Victims', The American Journal of Forensic Medicine and Pathology 12.2 (1991): 132; Richard P. Helmer, S. Rohricht, D. Petersen and F. Mohr, 'Assessment of the Reliability of Facial Reconstruction', in M. Y. Iscan and R. P. Helmer, eds, Forensic Analysis of the Skull (New York: Wiley-Liss, 1993); C. N. Stephan and M. Henneberg, 'Building Faces from Dry Skulls: Are They Recognized above Chance Rates?' Journal of Forensic Sciences 46.3 (2001): 432-440.

${ }^{10}$ C. N. Stephan, 'Facial Approximation - From Facial Reconstruction Synonym to Face Prediction Paradigm', Journal of Forensic Sciences 60.3 (2015): 566-571.

11 The current interest in so-called 'SciArt' and STEAM (as an extension of STEM, adding Art to the acronym) suggests that there is committed interest in recuperating aspects of this historical relationship from an educational perspective, despite a lack of clarity about the broadness of the terms of reference and power dynamics that may inform interdisciplinary collaborative work, which is rich in breadth, depth and international presence.
} 
demonstrative visual material for use in in legal proceedings, such as sanitized injury depiction via CGI ('body mapping'), motivated by a regard for the dignity of the victim, and the emotional burden of those present. It may also include the work of the court sketch artist who visually documents legal proceedings where cameras are forbidden; a special genre of visual reportage. In the interests of disambiguation, the capitalized phrase 'Forensic Art' is generally used to refer to expert facial analysis and depiction, including methods of producing or comparing images of the human face and/or skull, according to scientifically-assessed methods and standards. Such a proper compound noun suggests a discipline with agreed standards, principles and professional qualifications, which the practice cannot claim. I prefer the lower-case 'forensic art', which acknowledges the applied status of the 'forensic'; avoids any claims to 'Art' proper, and implicitly embodies an expanded field that includes spatial reconstructions and other forms of visual presentation used in court. Known as 'exhibits', these may also include material evidence, or visualizations of trace evidence interpreted through expert analysis and opinion.

Forensic art is usually practised by individuals working with law enforcement agencies, or those working alongside law enforcement in a freelance or consultative capacity. Over more than a century, the methodologies that have informed contemporary forensic facial depiction - which draws on studies in anatomy, facial growth and development, reconstructive surgery, dentistry, pathology, psychology and portraiture - have been developed and refined, but training and techniques are varied, so it stands to reason that the quality of forensic facial depictions can be described as wildly uneven. Practitioner experience may also be very varied; training within an academic environment may provide lab-based practice on historical remains but actual forensic field experience is limited, whereas working for law enforcement is entirely casework-focused. Research and consultancy work might attract a range of face-based work, whereas law enforcement may separate the work of facial identification (composites and comparisons) and victim identification (reconstruction and superimposition). The South African Police Service, for example, is structured in this way, with little communication between the two units. Practitioners work across a range of media, including drawing, sculpture and digital montage, often in combination. Likewise, techniques may be traditional (manual), digital (or a combination thereof) or fully automated. It is understandable, given the range of techniques and available technology, that the accuracy and quality of depictions reflects these variables. 


\title{
A Visage by Any Other Name
}

The ontology of images, particularly in disciplines which do not regard themselves as having visual cultures - science, law, geography and so on - has been given considerable attention by art historian James Elkins. ${ }^{12}$ The deployment of facial images within those disciplines arguably serve a more instrumental purpose than in visual art, where conceptual and symbolic attachments and inferences of the facial image are central. But it is the paradoxical universality and elusiveness of the face as a known - visible, legible - object that is of particular interest:

\begin{abstract}
As adults, we are usually complacent and secure enough to define faces as we see them - I see you, and I know which part of you is your face. But of course that is not defining a face; it is identifying one. It's an odd situation we find ourselves in, not being able to say for sure what faces are, because faces must be among the most important objects that can be seen. They are indispensable for relations of any kind, and our own faces (and people's reactions to them) tell us what kind of people we are. ${ }^{13}$
\end{abstract}

Our ideas about faces tend to be normative and anthropocentric. This is significant because of the way in which we understand the face as functioning as both an icon and index of human interaction. We perform our identities through our faces and ideas about ourselves are projected onto us by others. We can construct and enhance our facial appearance (make up or masks, surgery), or disease or trauma may alter our appearance temporarily or more permanently. As a biometric, it is a technology of identification. Deviations from the 'normal' face, the inability to make facial expressions (Moebius syndrome) or inability to recognize faces (prosopagnosia)

\footnotetext{
${ }^{12}$ J. Elkins, 'What is a Face?' in id., The Object Stares Back (San Diego/New York/London: Simon and Schuster, 1996, repr. Harvest, 1997); id., Picturing the Body: Pain and Metamorphosis (Stanford: Stanford University Press, 1999); id., Visual Practices across the University (Paderborn: Wilhelm Fink, 2007); see also W. J. T. Mitchell, Image Science: Iconology, Visual Culture, and Media Aesthetics (Chicago: University of Chicago Press, 2015). ${ }^{13}$ Elkins, 'What is a Face?' 161.
} 
operates as an injunction to 'normal' communication. Through the face, we relate to or reject one another.

Our assumptions about the co-ordinates of the human face are also reflected in our seemingly limitless capacity to project this idea of a face onto pretty much anything, animate or otherwise, even punctuation. Facial pareidolia describes the irresistible compulsion most of us have to project or read faces (and then expressive character), into all manner of inanimate objects from automobile design (headlights and front grills) to architectural structure to everyday objects. ${ }^{14}$ Our use of emoticons in short-form text messaging and social media platforms might seem terribly contemporary but as Jon Calame (2013) reminds us, satirical US magazine Puck published set of sophisticated 'proto-emoticons' in 1881, demonstrating complex emotions Joy, Melancholy, Indifference, Astonishment - with the simplest visual notation possible. ${ }^{15}$

We might be able to talk confidently about the shapes of faces from the perspective of anatomy, based on an understanding of the relationships between hard tissue (bone) and the soft tissues (muscles, skin and fat) of the face, and their particular structures and functions. ${ }^{16}$ From the perspective of cognitive psychology, the relationship between resemblance and recognition, and the role that representational styles play in either encouraging or discouraging us to recognize similarities and differences between facial depictions, throws up a different, but related set of

${ }^{14}$ Facial pareidolia even enjoys its own Twitter account Faces In Things @ FacesPics 15 J. Calame, 'Saving Face', Cabinet, 49 (2013): 28-31. This nascent 'typographical art' would find its digital maturity decades later with ASCII art, but what is really noteworthy is the correspondence between the emotional expression depicted here and those of the Facial Action Coding System, based on the work of Carl-Herman Hjorztsjö, Man's face and mimic language. Tr. W. F. Salisbury (Lund: Studentlitteratur, 1969/70) http://diglib.uibk.ac.at/download/pdf/782346?name=Man's\%20face\%20and\%20mimic\%20langu age [Accessed 30 March 2017] and adapted by Paul Ekman and Wallace V. Friesen, with a significant updated published in 2002: P. Ekman and W. C. Friesen, Facial Action Coding System: A Technique for the Measurement of Facial Movement (Palo Alto: Consulting Psychologists Press, 1978); id. and J. C. Hager, Facial Action Coding System: The Manual on CD ROM (Salt Lake City: A Human Face, 2002). FACS is used in psychology and animation to quantify and analyse the mechanics and affects of facial expression.

${ }^{16}$ B. A. Fedosyutkin and J. V. Nainys, 'The Relationship of Skull Morphology to Facial Features', in Iscan and Helmer, eds, Forensic Analysis of the Skull, 199-214. 
questions suggesting that the concept of 'likeness' is fairly fugitive or at least contingent. A mannerism or a 'look' can remind us of someone as much as slavish reproduction of features. This throws into confusion assumptions we have about concepts of 'realism', 'naturalism' and 'verisimilitude' relative to the facial image.

Designations such as 'portrait', 'likeness' and 'composite' all suggest particular conceptual and technical parameters regarding depictions of the human face. Of these, 'portrait' is the most complex as it designates not just an object, but a genre that is historically and ideologically determined, and which has generated a vast raft of scholarship, predominantly in the fields of art history and visual culture. ${ }^{17}$ It is after all a portrait, Leonardo Da Vinci's Mona Lisa (c. 150306), that is possibly the most famous (and most parodied) work of art in the world.

Within the field of human identification, questions of accuracy are played out in the terms of reference themselves. Accepted wisdom within the field is that forensic facial depictions do not (and should not) claim to function as a form of portraiture because of the inherent limits of what can either be predicted from the skull or depicted from memory. ${ }^{18}$ The most common designation for building faces from skulls is 'facial reconstruction', which is also the term most commonly used in popular media. But related epistemological impasses have provoked objections to the claims implicit in the term 'reconstruction' - that an 'accurate' face can be reproduced from the skull. The term 'facial approximation' has therefore been proposed as a more precise reflection of process and result. ${ }^{19}$ However, 'approximation' is more accurately used to describe fully

${ }^{17}$ Podro, Depiction; Richard Brilliant, Portraiture (London: Reaktion, 1991); Marcia Pointon, Portrayal and the Search for Identity (London: Reaktion, 2013).

${ }^{18}$ C. Wilkinson, 'Facial Reconstruction - Anatomical Art or Artistic Anatomy?' Journal of Anatomy 216 (2010): 235-250. Increasing attention is being paid to best-practice methods to optimize the possibility of identification (an already highly-contingent process) and minimize the introduction of error into the depiction itself: S. Davy-Jow, 'The Devil is in the Details: A Synthesis of Psychology of Facial Perception and its Applications in Forensic Facial Reconstruction', Science \& Justice, 53 (2013): 230-235; C.M.Wilkinson, 'A review of forensic art', Research and Reports in Forensic Medical Science 2015:5 17-24.

19 J. S. Rhine, 'Coming to Terms with Facial Reproduction', Journal of Forensic Sciences 35.4 (1990): 960-963; Stephan, 'Facial Approximation'; id. and M. Henneberg, 'Recognition by Forensic Facial Approximation: Case Specific Examples and Empirical Tests', Forensic Science 
computerized facial models that use fitting algorithms to match or 'wrap' a database-derived skin 'mask' to the target skull. Relying on statistical probability, and so eliminating highly characteristic features that we may associate with a specific individual face, such automated face models inevitably produce a facial 'type'. But forensic identification is specifically interested in unique features that identify a particular individual, and ideally aims to avoid misidentification wherever possible. As it is never possible to 'prove' identification with $100 \%$ categorical accuracy (despite claims made about DNA), the principle of exclusion should predominate, as misidentification has significant consequences.

'Facial reconstruction' is often - reasonably - confused with reparative, corrective or cosmetic facial surgery. While forensic depiction owes a debt to maxillo-facial and craniofacial surgical research, it is a different project. The alternative 'facial restoration' invokes the embalmer and their mortuary cosmetics which too, is a different project (although results can look uncomfortably similar). Further considerations concerning evidential weight (evidence vs intelligence); circulation (amongst the appropriate community for recognition) and lack of widely agreed standards are more accurately represented by the relatively neutral term, 'depiction'. Hence my preference for the phrase 'forensic facial depiction' as it embraces the full range of facial images produced from human remains or from eyewitness memory, in the case of suspect composites. It acknowledges the anthropological, anatomical and representational (pictorial or sculptural) skills required to produce an individual or 'characteristic' face from information obtained either through analysis of the skull or verbal description. Pictorial and sculptural methods both involve attention to the qualitative and quantitative aspects of individual features within the holistic face 'complex'. Creative interpretation by the artist must remain sensitive to the limits of this knowledge. We are not reproducing a face, but producing a "new face' with little, limited or corrupted visual reference material for the target face.

International 156 (2006): 182-191; Alan G. Morris, Missing and Murdered: a personal adventure in forensic anthropology (Cape Town: Zebra Press, 2011), p.87. 
'Depiction' therefore cautiously acknowledges the possibilities and the limits inherent to this work, echoing what Michael Podro recognizes from within visual art: 'Depiction has two main conditions: first our capacity to recognize through difference, and second, the intention to use the object that is materially present - the painting or drawing - to imagine what we recognize within it. ${ }^{20}$

\section{Faces from Memory}

In 2009, a story about the unlikely success of an eyewitness sketch went viral. The image, the most notional of drawings depicting the alleged murderer of a Bolivian taxi driver, has since developed the anecdotal reputation of one of the worst suspect images ever produced, and as such, makes for enduring 'listicle' fodder on websites like Buzzfeed. ${ }^{21}$ It is necessary to stress that this image was not made by a professional police artist, but by the eyewitness themselves. ${ }^{22}$ Nonetheless, a suspect was identified, arrested and convicted with little else to go on other than a thatch of thick, straight hair parted down the middle, which I am hazarding was sufficiently characteristic to pick him out from a crowd. So how and by whom should these facial images be produced? How are they expected to work? What forensic authority do they possess and how is this constructed?

Police composites (or 'artist's impressions') are facial depictions of criminal suspects, based on interviews with the relevant witness(es). There is variation in both composite and interviewing techniques; practitioners may use pencils or computer software, relying more or less on photographic reference catalogues or databases of features to compile a likeness. Recommended

\footnotetext{
${ }^{20}$ Podro, Depiction, 5.

${ }^{21}$ Patrick Smith, 'The 21 Worst Police Sketches Of All Time', BuzzFeed <https://www.buzzfeed.com/patricksmith/the-27-worst-police-sketches-of-all-time> [accessed 21 May 2017].

22 Rory Carroll and Latin America correspondent, 'Childlike Photo-Fit Leads Bolivian Police to Murderer', The Guardian, 24 November 2009, section World news <https://www.theguardian.com/world/2009/nov/24/bolivia-photo-fit-murderer> [accessed 21 May 2017].
} 
best practice is the cognitive interview, designed to retrieve stored memories via holistic context re-instatement, versus the brusque, 'just the facts, ma'am' investigative approach. ${ }^{23}$

Identikit and Photofit are two of the earliest manual, feature-based systems that enjoyed widespread use on both sides of the Atlantic since their introduction some four decades ago. The images produced by these systems possess a cultural endurance that is visual shorthand for phrases like 'suspect', 'fugitive', and 'person of interest'. Photofit replaced Identikit's catalogue of drawn features printed on acetate strips with photographic samples printed on rigid card, presumably to enhance the realism and by implication the accuracy, of the resulting representation. A witness would select features and assemble them like a Dada collage. Both systems offered the possibility of customizing the final image (manually adding facial marks or other characteristic features not offered by the stock images), but it remained difficult, if not impossible, to remove the demarcation lines that exposed the piecemeal, feature-based construction of the image. And the catalogue of available features was limited.

The problem is that with feature-based systems a fundamental error is introduced right from the start: it is a broadly accepted view that we do not encode faces feature for feature, and external features - hairstyle, facial hair - dominate our recall of unfamiliar faces (see Jane Draycott's chapter in this volume for the inseparability of hair from the face as a whole). Rather, we encode faces holistically, as a gestalt or organized whole. ${ }^{24}$ Only through the process of learning faces and becoming familiar with them, do internal features begin to dominate what we remember

\footnotetext{
${ }^{23}$ On composite techniques, see S. Mancusi. The Police Composite Sketch (New York: Humana Press, 2010); D. P. Hinckle. Mug Shots: A Police Artist's Guide to Remembering Faces (Colorado: Paladin Press, 1990); L. Gibson Forensic Art Essentials: A Manual for Law Enforcement Artists (Cambridge, MA: Academic Press, 2007); K. T. Taylor, Forensic Art and Illustration (Boca Raton: CRC, 2001). On the cognitive interview, see R.P. Fisher and R.E. Geiselman Memory enhancing techniques for investigative interviewing: The cognitive interview. (Springfield, IL: Charles C. Thomas, 1992).

${ }^{24}$ J.W. Tanaka and M.J. Farah 'Parts and wholes in face recognition', The Quarterly journal of experimental psychology, 46(2) 1993: 225-245; G.M. Davies, J.W. Shepherd, and H.D. Ellis. 'Remembering faces: acknowledging our limitations', Journal of the Forensic Science Society, 18(1-2) 1978: 19-24.
} 
about a face. This is why when a friend or relative changes their hairstyle or shaves their beard, we will most likely be able to pick them out from a crowd. ${ }^{25}$

Subjected to controlled experiments, facial images produced using feature-based systems did not produce a good match with the target face, 'even under the favourable (and unrealistic) condition where the target's face was visible during construction' ${ }^{26}$ Cognitive psychologists have made a strong case for the wholesale replacement of feature-based systems with a sophisticated, 'holistic face' approach, which has effected policy changes in the UK as to how such images are produced and forensically understood: according to Association of Chief Police Officers guidelines (2009), developed in line with the evidence base produced by laboratory research, initial composites are regarded as 'primary' exhibits, with any further modifications (morphed, animated) as 'secondary' exhibits. ${ }^{27}$ Technology has responded accordingly, with computerized compositing systems such as EvoFIT using evolutionary algorithms to 'breed' increasingly individualistic faces based on user selections from sets of similar faces that all conform, more or less, to a basic physical description. They can also be animated. ${ }^{28}$

${ }^{25}$ C. Frowd. 'Facial Composites and Techniques to Improve Image Recognizability', in T. Valentine and J.P. Davis (eds) Forensic Facial Identification: Theory and Practice of Identification from Eyewitnesses, Composites and CCTV (West Sussex: Wiley Blackwell, 2015), p.48. Of course, a significant point about the limitations of doing facial recognition research in laboratory environments versus 'in the wild', is that different cognitive processes are at work in processing still facial images versus faces in motion, within a specific context where a host of other distractors may be present. Having contextual information improves recognition rates. ${ }^{26}$ ibid., 46-7. The interview process, in which a facial description is elicited, plays a formative role in producing an image. Asking witnesses to make seven whole-face judgements regarding health, masculinity, pleasantness, honesty, distinctiveness, intelligence and likeability showed a striking improvement in accurate naming for composites produced using a feature-based system (a leap from $9 \%$ to $41 \%$, tested with PRO-Fit) as well as a holistic system (24\% became $39 \%$, testing EVOFit): ibid., 56. The marked improvement reported for the feature-based system seems to demonstrate the double effectiveness, and therefore necessity, of applying a holistic approach in both processes of descriptive recall and visual construction.

${ }^{27}$ ibid., 58-9, 63-4.

${ }^{28}$ The three commercial systems currently in existence are South Africa's ID, EFIT-V and EvoFIT: C. Tredoux, D. Nunez, O. Oxtoby and B. Prag, 'An Evaluation of ID: an Eigenface Based Construction System’, South African Computer Journal 37 (2006):90-97; 2006(37), pp.90-97; C.J. Solomon, S.J.Gibson, and J.J. Mist. 'Interactive evolutionary generation of facial composites for locating suspects in criminal investigations'. Applied Soft Computing, 13(7), 2013: 3298-3306; C. D. Frowd, P. J. Hancock and D. Carson, 'EvoFIT: A Holistic, Evolutionary 
Holistic composite systems enfold mathematical shape models with biological principles of sexual selection, described in terms of 'genetic algorithms'. As EvoFIT developer Charlie Frowd explains, variations on a set of reference faces can be generated by applying random co-efficient values, conceptualized as 'face genes', to the reference face data, with the result being 'a search of the space of possible faces and, ideally, evolution towards the relevant identity':

Genetic mutation can also be applied, an operation that replaces genes with a random value, the aim of which is to maintain variability in the population of faces. The resulting face has characteristic of both parents, with some variation. [...] The breeding process is iterated using faces that witness have selected from the (evolved) array. Note that this approach inherently involved chance due to the random nature of selecting (a) breeding pairs and (b) individual genes taken from each parent. The consequence is that sometimes a good likeness emerges early on, but at other times the evolution takes longer.

The final face can be further refined using a set of in-built 'holistic scales', which in addition to adjusting for age-related facial changes (slackening the jawline, for example), also allow for more qualitative value-based judgements such as 'health' and 'honesty': 'The accumulated effect of these 14 or so holistic scales can substantially improve the likeness of an evolved face' ${ }^{29}$

Facial Imaging Technique for Creating Composites;, ACM Transactions on Applied Perception (TAP) 1.1 (2004): 19-39; C. D. Frowd, P. J. Hancock, V. Bruce, F. C. Skelton, C. J. Atherton, L. Nelson, A. H. McIntyre, M. Pitchford, R. Atkins, D. C. I. Webster and J. Pollard, 'Catching more Offenders with EvoFIT Facial Composites: Lab Research and Police Field Trials', Global Journal of Human-Social Science, 11.3 (2011): 35-46. EvoFIT's website offers comprehensive information about the system, including links to published research. See http://www.evofit.co.uk/ [Accessed 15 May 2017].

${ }^{29}$ Frowd 'Facial Composites', 51-2. Susan Hayes and Cameron Tullberg, 'Police Witness Identification Images: A Geometric Morphometric Analysis', Journal of Forensic Sciences 57 (2012): 1487-94, note that the results indicate that compared with arrest photographs, witness identification images systematically depict suspects with lowered and medially located eyebrows. 
Holistic composite systems are designed to address what artists have long-known: we don't encode faces according to individual features, but we read them as a whole. Certainly, some people may have a single feature that is highly distinctive, which a skilled caricaturist would make function as emblematic of that individual, but we essentially read faces as a complex spatial topography, with features occupying the area in relative proportions to each other.

Given their conditions of production, composites are heavily contingent things, subject to the vagaries of eyewitness recall, the skill and experience of the officer conducting the interview and producing the image, the technology and the time s/he has available to do the job. Time figures as a feature from event through to artefact: the speed of the event witnessed; the time of day possibly affecting visibility; how soon after the event the witness provides a description; the length of time available for an interview; the time available to the forensic artist to produce an image; how soon (and where) the image is circulated and whether there is any media investment in keeping the story alive will all have an influence on the resulting facial image(s).

\section{Suspect Renderings: the conviction of Norman Simons}

The functions and limits under which composites operate are relevant for any facial depiction (reconstruction from the skull, age progression) produced as part of a forensic investigation. They are a specific kind of image, a pictorial statement designed to aid identification though generating leads and keeping an event alive in public memory. They are commonly referred to as secondary methods which may indeed lend support to primary methods, which in human identification terms is currently limited to scientifically-supported methods like DNA and fingerprinting. Since 1993, the Daubert standards, a set of principles that determine whether evidence is based on scientifically-valid reasoning appropriate to the matter at hand, have governed the admissibility of any evidence presented in court. ${ }^{30}$ As expert practitioners, these standards apply equally to the forensic artist or facial identification officer.

${ }^{30}$ Daubert Standard (definition). Legal Information Institute, Cornell University Law School. Available at https://www.law.cornell.edu/wex/daubert_standard. [Accessed 15 January 2017]. 
The troublesome case of Norman Avzal (Sarfaraaz) Simons, convicted in Cape Town in 1995 of being the notorious Station Strangler, has the dubious reputation of flouting these fundamental principles. It is one example where a police composite - and visual identification methods in general - carried specious evidential weight in a case that was already deeply fraught in sociopolitical terms, and remains controversial. The process that identified Simons as a suspect, and then the ways in which he was 'made into an image' remains doubly suspect, in both senses of the word.

The hunt for the Station Strangler - 'the largest hunt for a serial killer in South African criminal history' - began at the height of Apartheid South Africa's State of Emergency in 1986, spanned the release of Nelson Mandela from prison in 1990 and culminated in an arrest in April 1994, only days before that country's first democratic national election. ${ }^{31}$ Over this period the decomposing bodies of 22 pre-teen and teenage boys who had gone missing from in and around the sprawling settlement of Mitchell's Plain, a visually bleak, impoverished and crime-ridden area known as the Cape Flats, had been found dumped, some in shallow graves, in the surrounding dunes. The stress this case placed on the communities directly affected by it was considerably amplified by the acutely febrile political situation in South Africa at that time. Traumatized, disenfranchized and angry people were pushed to breaking point, and there was intense pressure to make an arrest. The hunt gained real momentum when a young boy, Ryno van Rooyen, reported his brother, 10-year-old Elroy van Rooyen, missing after they'd helped a man carry boxes from a local shopping centre towards a nearby train station on 11 March 1994. Van Rooyen's remains were found shortly thereafter in similar circumstances. An eyewitness, Fouzia Hercules, was found who corroborated Ryno's account, which allowed police to identify a viable suspect: ex-Mitchell's Plain schoolteacher Norman Simons.

${ }^{31}$ Candice Bailey, 'Revisiting the Station Strangler Cases', IOL (Independent Online), 16 August 2005. http://www.iol.co.za/news/south-africa/revisiting-the-station-strangler-cases-250970. [Accessed 15 January 2017]. 
Although 22 boys were thought to be victims of a single serial predator, Simons would only be convicted of Elroy's abduction and murder. He had eventually confessed to this murder during questioning, but later retracted. The case against Simons otherwise rested on visual identification, a composite construction to which both witnesses contributed, and an identification line-up, where Ryno was unable to positively identify Simons, but Fouzia did. Simons received a 25-year sentence for murder and a further 10 years for kidnapping, effectively sentenced to life in prison. His 2015 parole application was unsuccessful.

Three different composites were produced with the participation of both witnesses, which according to Hercules' evidence took place eleven days after Elroy's abduction, on 22 March. The trial judge recounts Ryno's testimony in his judgement: 'The police showed them a lot of pictures of ears, noses, mouths and so on. She and he looked at them together because they had to say how the man's eyes, his nose and his mouth looked. The police officer then showed them a picture that looked like the man who took Elroy away. ${ }^{32}$ From this account, we learn that the facial identification officer produced three 'drawings', which were entered into evidence as Exhibits J, K and H. At the judge's request, these were shown to Ryno? during his testimony, and 'he immediately pointed out Exhibit $\mathrm{K}$ as that of the man who took Elroy away'. ${ }^{33}$

Exhibit K received special mention in the trial judgement, with more than a full page's worth of commentary relating to the 'clear similarities in facial features, eyes, nose and mouth between the face on the identikit ... and the accused's face', an unprecedented move that confers undue evidentiary weight to what is at best, an average composite produced under questionable circumstances, but ultimately confers responsibility onto the defence to take issue with admissibility or by extension, any prejudice that may have arisen as a result thereof:

... Exhibit $\mathrm{K}$ is largely in line with the accused's face, has not been contested by the defense or refuted by any other evidence [or witness].

\footnotetext{
${ }^{32}$ The State versus Norman Sarfaraaz Simons (High Court of South Africa, Good Hope Provincial Division, 1995), SS.104/94: 1404-5

${ }^{33}$ ibid.
} 
... viz. Exhibit $\mathrm{K}$ and the accused's face, where similarities are apparent from a comparison of the accused's photograph (Exhibit L) with Exhibit K, except for the scar, which is prominent on the identikit and looks like a cut. However, the accused has visible dark-coloured scars or other lesions [marks] under his right eye, as can be seen clearly on the pictures Exhibits L and Dl and D2. As can be seen in the photograph, Evidence $\mathrm{CCl}$, the accused's hair may be "combed up" higher than it was when Evidence L was taken.

[...] It is also common cause that no photo or identikit of the accused - or the suspect - was published before Fouzia Hercules made a statement to the police on 22 March and the identikit, Evidence K, was drafted. ${ }^{34}$

Three years later, the judgement in Simons' unsuccessful appeal against his guilty verdict also makes reference to the 'striking resemblance' the identikit bears with 'the face of the appellant':

The only material difference is the style in which the appellant's hair is combed, but [the fact] that he combed it like that on occasion emerged via another witness. [...] And as far as the reliability of her identification is concerned, it is substantiated by the identikit, and the confession to which I will shortly refer. ${ }^{35}$

Both judgements make reference to both a distinctive facial mark - a large, permanent and pigmented scar on Simons' right cheek which is referred to by one judge as a 'cut' (quite a different thing) and an easily alterable external feature (Simons' hairstyle) as key points of comparison. Simons in fact objected to being the only person included in the identification parade with a facial scar. Recalling the salience of external versus internal features in the context of unfamiliar faces, Frowd points out that external features are important in the naming process: it is difficult to identify faces with only internal feature information, but including external features at the early stages of producing a composite can be a distraction. ${ }^{36}$

\footnotetext{
${ }^{34}$ State v. Simons 1995: 1407, my emphasis.

${ }^{35}$ Avzal Sarfaraaz Simons versus The State (South African High Court of Appeal 1998), SS104/1994: 4-5

${ }^{36}$ Frowd 'Facial Composites', 2015: 54
} 
Judicial verdicts in the Simons case are written in Afrikaans, the administrative language of the Apartheid Nationalist government which understood the power of language as a tool of exclusion and control. The quotes are my own translations, and in doing this work, I was reminded of the difficulty of the word 'getuienis', which means both 'testimony' and 'evidence', in the sense of the act of providing it. 'Evidence' as an object is 'bewysstuk'; 'bewys' can also be translated as 'proof', to demonstrate something to be truthful. It is in this act of translation that the difficulty of imposing forensic responsibilities on an object of intelligence, might gain a dark import, and demonstrates how open objects are to mobilisation.

Inhabiting the eye of a perfect storm of social and political upheaval, the legal outcome of the case is regarded as having severely limited integrity. A facial identification research group in the Department of Psychology at the University of Cape Town has reconstructed the visual identification practices used by the police in two experiments in a controlled, laboratory context. ${ }^{37}$ The first experiment set out to test whether the line-up was obviously biased against Simons. It asked participants to identify the guilty suspect from the (admittedly poor quality) video. Played silently, participants only had low-resolution visuals to work with, making judgements based on behaviour and body language; out of 80 participants, not one picked Simons. A second experiment tested resemblance between the composite and 50 randomly chosen faces matching Simons' ethnic appearance (one photograph in the array was of Simons). To prevent participants from choosing Simons merely because of the distinct scar (or 'cut') visible on the composite, researchers placed a plaster in the same position on all faces in the array. Simons was the third most frequently chosen face, but he was more likely to be selected out of a larger group of faces than an array including fewer choices.

${ }^{37}$ A. Nortje, C. G. Tredoux, K. Kempen and A. Vredeveldt, 'Applying Laboratory Techniques to a Real-Life Case: What Insight can we Provide about the Station Strangler Case?' Poster presentation at the American Psychology-Law Society Annual Conference, Portland, United States, March 2013. 
However likely Simons is as the perpetrator, there has been sufficient post-conviction revision to suggest that his guilt was not proven beyond a reasonable doubt in the terms of hard evidence. ${ }^{38}$ In lieu of this, we are left with the disturbing precedent that a high court judge, as well as a team of three appeals court judges considered a composite image to have adequate authority to act in lieu of any physical evidence linking Simons to the case, and use this to support a murder conviction and life imprisonment.

\section{Quantifying Likeness: Questions of Materiality}

An ideal accuracy study should set out to measure the range of variables that determine facial appearance - morphology, proportion, textural resemblance - in relation to method and technique. This is frequently a challenge: forensic cases based on skeletal remains may never be identified, and if they are, the quality of an available ante-mortem photograph is often poor, and only lends itself to two-dimensional visual (proportional and morphological) comparison. Medical imaging technology now permits in vivo 3D analysis of facial reconstruction methods, where morphological deviation between subject and model can be mapped. ${ }^{39}$ Reliable photographic images will not however exist for historical individuals prior to the mid-nineteenth century. Other visual depictions, such as portraits, etchings, honorific sculpture and possibly a life/death mask may exist for notable individuals post- $17^{\text {th }}$ century. The Manchester method, socalled because it was developed within the now-closed Unit of Art in Medicine at the University

\footnotetext{
${ }^{38}$ Simons himself and his lawyer have maintained this position from the beginning. This is not particularly surprising. More striking is the way the conversation recently re-entered the public imaginary in the context of a procedural parole hearing: https://traveltrailtony.wordpress.com/category/informative-articles/ http://www.iol.co.za/news/crime-courts/shofer-was-the-station-strangler-2053684

${ }^{39}$ See W.-J. Lee, C. M. Wilkinson and H.-S. Hwang, 'An Accuracy Assessment of Forensic Computerized Facial Reconstruction Employing Cone-Beam Computed Tomography from Live Subjects', Journal of Forensic Science 57.2 (2012): pages; W. Lee, S. Mackenzie and C. M. Wilkinson, 'Facial Identification of the Dead', in S. Black and E. Ferguson, eds, Forensic Anthropology 2000-2010 (Boca Raton: Taylor and Francis, 2011), 363-394; S. Decker, J. Ford, S. Davy-Jow, P. Faraut, W. Neville and D. Hilbelink, 'Who is this Person? A Comparison Study of Current Three-Dimensional Facial Approximation Methods', Forensic Science International 229 (2013): 161.e1-161.e8; K.Smith, 'The Doppelgänger Effect? A comparative analysis of forensic facial approximation methods'. Unpublished thesis, University of Dundee, 2013
} 
of Manchester combines facial anatomy and mean tissue depths, developed by Richard Neave after the Russian (Gerasimov) and American (Gatliff) methods. Photographic superimposition was then used to compare reconstruction with portrait, demonstrating a range from extreme accuracy to identifying an instance of the wrong portrait being associated with a particular mummy. This method was first introduced in the Buck Ruxton case and more recently given credit for producing the 'forensic aesthetics' of popular culture via the images produced by Richard Helmer in support of the forensic identification of Joseph Mengele. ${ }^{40}$

Where no reliable comparison image exists to assess accuracy and likeness, suspect composites may offer at least an image-to-image comparison if the target individual is eventually arrested. In 2013, a group of researcher led by Scott Klum published a study that set out to test two different modalities - 'sketches' (drawn) vs 'composites' (using software) based on eyewitness accounts to mugshots of the perpetrators. The team gathered 75 forensic sketches, 50 of which were drawn by 'the world's most successful forensic artist' Lois Gibson, ${ }^{41}$ who serves the Houston Police Department, with the balance produced by forensic artists employed by the Michigan State Police. Arrest photos (mugshots), presumably resulting from the arrest of these individuals based on the sketches, were then used as experimental stimuli, and shown to a group of volunteers. Two days after viewing the mugshot, the group of volunteers used a facial composite software to produce images of these 'suspects' from memory. Memory of the photograph, that is, not a memory made in a real-life scenario. The research team then subjected the forensic sketches and

\footnotetext{
${ }^{40}$ See Caroline Wilkinson's chapter in this volume, and B. Brier and C. Wilkinson. 'A Preliminary Study on the Accuracy of Mummy Portraits' ZÄS 132(2005): 111; J. Prag and R. Neave, Making Faces. London: British Museum Press, 1999); C. Wilkinson, Forensic Facial Reconstruction (Cambridge: Cambridge University Press, 2004/8); J. Glaister and J.C. Brash, 'Medico-legal aspects of the Ruxton case', Vol. 33 (Livingstone, 1937); Thomas Keenan and Eyal Weizman, Mengele's Skull: The Advent of a Forensic Aesthetic (Berlin/Frankfurt Sternberg Press/Portikus, 2012).

41 'The World's Most Successful Forensic Artist: How Lois Gibson's Incredible Sketches Have Helped Solve Thousands of Crimes', Guinness World Records, 2017 <http://www.guinnessworldrecords.com/news/2017/1/lois-gibson-facing-crime-with-worldrecords-458852> [accessed 21 May 2017].
} 
the computer composites to a 'recognition accuracy' analysis using two different automated face recognition systems. ${ }^{42}$

This the only study I have found that attempts a quantified comparison of different representational registers. However, inherent problems may render the findings not very useful, for example: it is questionable whether the role of the volunteers within the controlled study really did '[mimic] a witness of an actual crime scene' as the researchers claim; and some of the composite drawings by Gibson contain details - angle of head, lighting across the facial surface - that are uncannily similar to the mugshot taken at arrest. This visual similarity prompts the question of whether she adjusts the published versions of her sketches after having had sight of the mugshots, or whether she has developed a drawing style that deliberately mimics the unforgiving frontal view of the mugshot, in which case an argument could be made for introducing implicit prejudice at the stage of the composite.

Two years prior to Klum et al's study, Susan Hayes and Nick Milne, representing an interdisciplinary collaboration across visual art and human biology, published the results of a study which attempted to quantify the differences between a photographic reference image and a portrait drawing of the same subject, across a cohort of 30 individuals. Their specific contribution was the novel application of geometric morphometrics (GM) to facial depictions, in addition to the more conventional methods of visual assessment and anthropometry. Of the three analytical methods used, they express confidence in GM's ability to quantify tendencies within an individual artist's style, and suggest that the method has wider application across a range of facial depictions. ${ }^{43}$

\footnotetext{
${ }^{42}$ S. Klum, H. Han, A. K. Jain and B. Klare, 'Sketch Based Face Recognition: Forensic vs Composite Sketches', International Conference on Biometrics, IEEE (2013): 1-8. See also G. Davies, H.D. Ellis, and J. Shepherd, J. 'Face recognition accuracy as a function of mode of representation', Journal of Applied Psychology, 63(2),1978: 180-187.

${ }^{43}$ Susan Hayes and Nick Milne, 'What's Wrong with This Picture? An Experiment in Quantifying Accuracy in 2D Portrait Drawing', Journal of Visual Communication, 10 (2011): 149-74.
} 
In simple terms, GM offers a set of analytical tools to talk about the differences between shapes in mathematical space in statistical terms. It is typically applied to the study of variation in biological forms; here the authors treat portrait drawings as biological forms in themselves, 'to find out how an individual artist changes the shapes of a sitter's face' expressing an interest in what they call intended versus 'unintentional' distortions that may be present in the drawn portraits. Intended distortions are those choices we make about highlighting characteristic features. As they observe,

while both exaggeration and generalization do not constitute a mimetic rendering of an individual's facial appearance, they are not entirely inaccurate either. The more tangible transformations that occur in the translation of a living person into a traditional 2D portrait tend to be somewhat less than desirable; that is, largely unintentional manipulations of the sitter's facial shapes which more often than not are unintended side-effects of the processes involved in visual perception. $^{44}$

In their experimental design, all the drawings were made by one artist (Hayes), and were initiated in the presence of the volunteer subject. In other words, a 'life drawing' session of varying length allowed for direct observation at first. At the session's conclusion, a reference photograph of the sitter was taken from which the drawing was later completed. Of course, this also means that multiple processes of translation are taking place here - from direct observation, to photographic representation, and then the drawing being a further (hybrid) translation of both.

Calling on canonical figures in art history and theory - Richard Brilliant, Ernst Gombrich and Roger Fry among others - to address issues of accuracy and likeness in portraiture, Hayes and Milne frame a position that prioritizes portraiture's mimetic function. They work to separate the genre from its aesthetic values, stressing its artisanal and mechanical aspects. Their findings are, in their words, 'at best partial': the drawings were not 'pure outlines', and GM cannot measure

${ }^{44}$ ibid., 149. 
degrees of texture and shading that we translate into shape information. The portraits that did demonstrate better shape accuracy according to GM principles were judged better likenesses, 'but not significantly so.' 45

Hayes and Milne acknowledge that absolute mimesis (whatever this might be) cannot be achieved, acknowledging Gombrich on the inevitable influence of factors extrinsic to pure optical recording that will affect representational 'translation' of a real human face into an image of one on a page: the choice of medium (conté crayon in this case); the socio-political and cultural contexts of the production and reception of images; and that qualitative factors such as time, and the nature of interaction between artist and subject, are complex to quantify.

Artists are well-versed in the paradox that slavish pictorial mimesis can in fact work against the effect of likeness. Podro notes providing too much detail - representing each facial detail with equal attention - is less convincing than a depiction which balances salient details well-described with more open or 'provisional' areas and allowing our imaginations to interpolate between these to 'produce' the face (or whatever object we are contemplating). ${ }^{46}$ This finds a parallel in studies which suggest that photo-realism may be operationally detrimental in a forensic context; facial depictions produced with a photographic level of 'accuracy' may in fact reduce the possibility of the individual being recognized. Theoretically, any mimetic slip may cause us to reject the image, even if it mostly resembles the target face. 'A good likeness, therefore, is not an accurate likeness, but one that has an illusion of accuracy. ${ }^{47}$

Criticisms levelled against artistic subjectivity usually attend to repeatability. However, the significant difference in context between controlled studies undertaken in laboratory contexts and the contingencies of field operations should be taken seriously. A 'gold-standard protocol'

\footnotetext{
45 ibid., 150, 169.

${ }^{46}$ Podro, Depiction, 28.

${ }^{47}$ Hayes and Milne, 'What's Wrong?', 151, my emphasis.
} 
for testing composite systems in the lab, suggests that the issue of subjectivity and error is less an artistic problem and is more fundamentally a human one:

As constructors typically produce rather different-looking images for a given target $[\ldots]$ the protocol also recommends that at least eight constructors be recruited per system. Similarly, evaluators vary in recognition ability and so at least eight evaluators should attempt to name each composite. ${ }^{48}$

\section{Distorting the Image Corrects Perceptual Errors}

Within visual arts practice, it is a basic rule-of-thumb that considering an image from different angles, whether in the studio or in a gallery, is essential to assessing formal strengths and weaknesses, and overall compositional integrity. It is as true for non-figurative (abstract) work as it is for figurative representations. It is necessary to shift one's perspective in relation to the object, by stepping away and regarding it from a distance and from different angles, masking sections to view areas in isolation and then in relation to the whole. Details may look convincing close-up and in isolation, but may get lost in the composition as a whole. I have always found it useful to photograph work in progress, and assess it via a single-generation mediation. This process reintroduces an objective perspective that can get lost in the haptic intimacy of making. Uncannily, criminalistics pioneer Hans Gross described something very similar in the late nineteenth century:

The photograph is the image reflected by a mirror but it is a fixed image; this definition itself proves that photography, however paradoxical the assertion may appear, shows us more than the eye, even when it shows us no more than the eye can see. [...] A painter, ... after having worked for a certain time, places his portrait before a mirror and considers the image which the latter reflects; he often discovers great faults which he was incapable of seeing upon the portrait itself. The reason is that when one looks for a long time at an object, ... one

\footnotetext{
${ }^{48}$ Frowd 'Facial Composites', 2015: 49. 'Constructors' are shown faces with which they are unfamiliar, and after a specific delay, recall the face within an interview context with a trained professional. 'Evaluators' are those familiar with the target face who are asked to perform a recognition task with very basic contextual information.
} 
always sees it under the same aspect, which prevents certain defects being noticed; but when the image is reflected by the mirror one sees the object under lateral inversion and in consequence under another aspect; details may then perhaps be discovered which have formerly escaped notice. In photography exactly the same may be said; an object has been observed with great minuteness and application; a whole series of observations have been made regarding it; nothing striking has been noticed about it because one has become accustomed to its appearance; but if it be photographed, the new colour, the new situation, and the new aspect enable us to see it from another point of view and reveal fresh details which have not yet been discovered. ${ }^{49}$

The knowledge gained by 'looking awry', is well-known within visual arts practice. That it now has an evidence base via cognitive psychology is very encouraging. Recognition studies have shown that subjecting a facial image to a 'physical linear stretch' (doubling its height or width) has been found to 'substantially' improve correct naming, despite a concession that 'stretched images look distorted and inappropriate for the serious application for which they are used' ${ }^{50}$ This can be mitigated, they suggest, by looking at an image side-on, which creates a similar effect that is perceptual rather than physical. The future of improved composites performance therefore appears to be with multiple viewpoints, if not full three-dimensional composites: 'A multi-view model should be able to accurately render differences in perspective, so that the image at construction is a better match to the image seen at the crime scene.... The same principle may be applicable to other factors such as lighting and facial expression, ${ }^{51}$

\section{Looking Awry: Super Noi and Portrait Machine}

Whilst research aimed at understanding visual cognitive processing can be instructive, looking at how professional contemporary artists co-opt facial recall techniques offers another way of

\footnotetext{
${ }^{49}$ Hans Gross, Criminal Investigation: A Practical Handbook for Magistrates, Police Officers and Lawyers (1893, English translation 1907), cited in Greg Siegel, 'The Similtude of the Wound', Cabinet vol (2011), 99.

${ }^{50}$ Frowd 'Facial Composites', 2015: 61, but contradicted/nuanced by ibid., 65, citing C.H. Liu, and A. Chaudhuri, 'Reassessing the 3/4 view effect in face recognition. Cognition, 83(1) 2002: 31-48.

${ }^{51} i b i d ., 65$.
} 
'looking awry'. In the hands of those with both technical and conceptual expertise, and an unwillingness to accept given forms, committed instead to literal and figurative acts of deconstruction, the deadening effect of metric evaluation opens up to often tongue-in-cheek poetics of chance and intention, presenting parallel enquiries that thicken and enrich our understanding of the complexities of depicting the face.

In the 1990s, Italian artist Maurizio Cattelan, a conceptual artist who perpetually claims to 'have no ideas', embarked on a project he dubbed Super Noi ('Super Us'), collections of composite drawings of the artist constructed by police artists in different cities based on verbal descriptions provided by close friends and acquaintances, which capitalize on Cattelan's distinctive physiognomy. The various iterations of the work - sometimes referred to as Il Super Noi or suffixed with a specific city name like Bologna, Torino, New York - comprise 50 drawings per set on A4-size sheets of acetate..$^{52}$ They are wall-mounted, cloud-like arrangements, which sidesteps the temptation to foreground the modernist-bureaucratic associations of such images by displaying them in a rationalist grid. Representing 'a network of other people's appraisals', the effect is 'a kaleidoscopic representation of an individual', playfully calling into question the fundamentally contingent nature of a profession intended to be forensically precise. ${ }^{53}$ The title itself is suggestive of a conceptual portmanteau, linking the psychoanalytic theory of the Super Ego, by which we internalize social rules and behavourial norms, with the personality 'disorders' of schizophrenia or Multiple Personality Disorder.

Performing the paradox of identity as simultaneously that which defines the 'self' and which one seeks to escape, Cattelan's fragmentary and serial rogue's gallery is a humorous but ultimately complex mediation on perception, representation and judgement. He entertains his criminal fantasies in the visual language of suspect apprehension. He has said of the work: 'That piece was really about how people around you perceive you in different ways than how you really are.

\footnotetext{
${ }^{52}$ Maurizio Cattelan Il Super Noi http://www.laboralcentrodearte.org/en/recursos/obras/supernoi-torino-1996

${ }^{53}$ Guggenheim Education Teacher Resource Unit, 'Maurizio Cattelan All', 2011 Online: https://www.guggenheim.org/arts-curriculum/resource-unit/maurizio-cattelan-all. [Accessed 24 May 2017]
} 
So I was thinking about visualizing the idea of the self. The drawings really looked like me, but at the same time they were like cartoons. They were terrific. I don't know if it was a fluke' ${ }^{54}$

The 'composite-Cattelan' advanced by this work clearly demonstrates what the artist recognizes about the simultaneous likeness and caricaturish 'un-likeness' that emerges when a facial image is produced from verbal description. UK-based South African artist Trasi Henen's Portrait Machine (2011 - ongoing), takes this even further. ${ }^{55}$

Henen describes Portrait Machine as 'an ongoing, participatory drawing project that is concerned with interpersonal exchange, subjectivity, perception, collaboration and conversation'. An experiment in perception, practice and pedagogy, the project triangulates the relationship between sitter (subject), describer, and artist, performed as a one-to-one reciprocal exchange, with Henen acting as describer and artist and sitter switching roles after the first drawing is completed, and then one-to-many, performed with groups of art students in real time but not necessarily in real space - some sessions were conducted with Henen describing a subject via Skype. While spatial arrangements have been varied, all participants have consistently comprised either artists, designer/illustrators or art students; in other words, all have a measure of visual training.

Portrait Machine anticipated cosmetic brand Dove's 2013 US campaign film, Real Beauty Sketches (You're More Beautiful Than You Think) featuring forensic artist Gil Zamora. Here forensic art skills are harnessed to demonstrate the difference in self-perception (generally

\footnotetext{
${ }^{54}$ A great fan of gangster and heist films, Cattelan's practice is peppered with pranks and thefts, as well as a host of self-portraits of varying scale and bodily fragmentation, 'a battery of lookalikes, mini-mes, doubles, and surrogates'. He toys with the obsession the world of art has with the authentic signature (the mark of the self); celebrity culture's 'self as brand' (Cattelan occupies both worlds); and the agency of reinvention: the most famous person you'll never see: Guggenheim 'All', 2011; V. Nussbaum, 'Serial Künstler: Portrait of the Artist as a Malefactor', in C. MacLeod, V. Plesch and C. Schoell-Glass, Elective Affinities: Testing Word and Image Relationships (Amsterdam: Rodopi, 2009), 212.

55 T. Henen, http://portraitmachine.blogspot.co.uk/
} 
heavily self-critical) and perception by others (more generous) among a diverse group of female participants. Waiting-room-style encounters were set up between women who were strangers to one another. Entering Zamora's studio individually and with the artist screened from view, Zamora asks each woman to describe herself. In a separate session, he asks them to describe the woman they had just met. The resulting finely detailed pencil sketches were exhibited side-byside, with emotional commentary by the participating women. ${ }^{56}$

With Henen's consent, I staged Portrait Machine with a group of undergraduate ( $2^{\text {nd }}$ year) Fine Art students at the University of Stellenbosch in 2014. I had been on sabbatical from the university for the previous 18 months, so this group of students would not yet have encountered me within their teaching context. Hidden from view behind a screen, I listened as a teaching assistant, who would also act as witness-constructor', introduced the exercize to the class. The assistant proceeded to describe my appearance, avoiding words which might prematurely reveal my identity (gender pronouns for example), and the class attempted to translate her words into a facial image. The class had an opportunity to request any further salient information before completing their drawings. I stepped out from behind the screen to a mixture of laughs, cries of dismay, and 'Oh, I thought it was you!'

Having had rigorous cognitive interview and compositing training myself, it was this experience which really brought home the significance of descriptive language, the effects, as Henen writes of 'the speaker [acting] as the scribe's eyes'. What words and analogies are shared or missed between witness and artist? The possibilities and failure of language is ultimately what Portrait Machine foregrounds: hearing yourself described, and the unspoken self-censorship that might very well be occurring if the describer doesn't want to offend is an uncanny and acutely selfconscious scenario, which is amplified by then being faced with multiple versions of oneself, produced simultaneously and in real time, by a diverse group of people many of whom are

\footnotetext{
${ }^{56}$ Dove Real Beauty Sketches https://www.youtube.com/watch?v=litXW91UauE
} 
equally self-conscious about 'getting it wrong' (despite there being no way of getting it right, although I think one got very close indeed).

\section{Constructing Fugitive Subjects: prosopopoeia and the counter-forensic}

Translating the living face to facial image with incontrovertible fidelity eludes human ability. An essential factor, some fundamental animating spirit, escapes synthetic reconstruction. Paradoxically, this is amplified when we strive for mimetic realism without the necessary exceptional technical skill, and more tolerated when our depictions attend only to salient or characteristic details, or when our abilities can only manage the most rudimentary of sketches. As the various case studies discussed here show, representational style and technique, along with technical facility and dimensional translation, have a material effect on how the image does its work. As for the rest, it is a question that continues to vex and exercise those invested in understanding the social, cultural and legal authority of the facial image. Considering time and language as significant contributing factors to their particular materiality, composites are presented as embodying the 'fugitive', in both literal and figurative terms, exploring the limits of portraiture, the relationship between verisimilitude and the 'real', the image as record and performing the Self. Subjecting the ineffable qualities of portraiture to various metric analyses may get us some way, but it feels a little too much like Narcissus staring at his own reflection in a pond, an exercise in hubris.

In our current climate, where the relationship between identity and identification is increasingly contested and constructed (via selfies and other online avatars), the facial image and the self are related yet discrete conceptual entities. Within the humanities, interest in the face as an object of study can be understood as an extension of identity and body politics into 'critical subjectivities' that coalesce in different periods, aligning with various disciplines and discourses that frequently overlap (cultural studies, anthropology and philosophy, or psychoanalysis and criminology, for example). Yet despite inhabiting a world made of faces - or certainly, pictorial representations of faces - only a limited number of contemporary scholars in the humanities and social sciences - 
have begun to focus closely on the face itself. ${ }^{57}$ Within an expanded art history, the work of Hans Belting is instructive. ${ }^{58}$ This wave of recent scholarship suggests that the fugitive nature of the face (temporary and surgical cosmetic procedures being a rather literal case in point) is being recognized in newly complex ways. Deleuze and Guattari's complex and rather abstracted notion of 'faciality', which offers a machinic counterpoint to Emmanuel Levinas's empathic concept of 'the face of the other', seems to resonate with the politics of 'facelessness', as well as our current digital culture where images are being made by and for machines, which means that a large part of what we understand as 'visual culture' is in fact invisible to humans. ${ }^{59}$

So, in the spirit of looking awry, I conclude with an introduction to two concepts I will be taking forward in my future work that considers forensic art in an expanded sense, reproducing the faces of the vulnerable or the violent in the pursuit of justice, whilst also attending to the more fugitive aspects of the roles faces play in our contemporary lives. The arguments advanced here pivot on a central idea about the function of forensic art in the context of wider practices of scientific methods of human identification: their basic function is to facilitate and enact the translation of object to subject, which they achieve in inherently narrative and metaphorical

${ }^{57}$ Apart from the authors in the present volume, see Suzannah Biernoff, 'The Rhetoric of Disfigurement in First World War Britain', Social History of Medicine 24.3 (2011): 666-685 ; ead., 'Medical Archives and Digital Culture', Photographies 5.2 (2012): 179-202; ead., Portraits of Violence: War and the Aesthetics of Disfigurement (Ann Arbor: University of Michigan Press, 2017); Heather Laine Talley, Saving Face: Disfigurement and the Politics of Appearance (New York and London: New York University Press, 2014); Jenny Edkins, 'Forensic Identification' in Missing: Persons and Politics (Ithaca and London: Cornell University Press, 2011); ead., Face Politics (London and New York: Routledge, 2015); Sharonna Pearl, About faces: Physiognomy in nineteenth-century Britain (Harvard: Harvard University Press, 2010); ead., Face/On: Face transplants and the Ethics of the Other (Chicago/London: University of Chicago Press, 2017).

${ }^{58}$ Hans Belting, Face and Mask: A Double History, trans. Thomas S. Hansen and Abby J. Hansen (Princeton/Oxford: Princeton University Press, 2017).

${ }^{59}$ Gilles Deleuze and Felix Guattari, 'Year Zero: Faciality', in id. A Thousand Plateaus Capitalism and Schizophrenia, tr. Brian Massumi (Minneapolis and London: University of Minnesota Press, 1987); Levinas, 'Exteriority'; id., 'The Face'; T. Paglen. 'Invisible Images (Your Pictures are Looking at You), The New Inquiry, 8 December 2016. Online https://thenewinquiry.com/essays/invisible-images-your-pictures-are-looking-at-you/ [Accessed 8 December 2016] 
ways. They need stories to be told about them, stories that are most often told in reverse, reconstructed from debris and data collated post hoc.

The Forensic Architecture group's advancement of the concept of 'forensis' retrieves the public and by extension political, imperatives of the 'forensic' as embodied in the etymology of the word, the forum, a public space that foregrounds courageous critique and challenge, not simply immutable authority. ${ }^{60}$ The language and forms of forensis are performative. The objects that bear the responsibility of truth-telling are mute witnesses until someone demonstrates their significance to us. In other words, they require interpretation and translation. These objects have to be made to speak, or rather, conditions have to be designed to enable them to do so.

Thomas Keenan has identified and transposed the concept of prosopopoeia - a concept innately tied to the face - as a way of understanding how objects function within a forensic context, where absent, imagined, or dead persons or things are represented as 'speaking'. ${ }^{61}$ As performative technology, collected evidence and court exhibits are mobilized to do the work of testimony, made to speak via the interpretative skills of an expert witness, making representations on behalf of those who cannot, and giving a face and voice to inanimate things including abstract concepts like 'city' and 'state', 'enabling claims to be made, positions to be taken, justice to be pursued' ${ }^{62}$ Here, material and immaterial things are crafted as objects of authority and truth.

The Simons case demonstrates the challenge to individual liberty than can result when a number of intensely contingent factors can come together to differentiate someone as exceptional, based not only on their facial appearance, but also how this notionally translates into an image produced under stressful circumstances. Here, investigators and legal representatives chose to

${ }^{60}$ Eyal Weizman, 'Introduction: Forensis' in Forensic Architecture, ed, Forensis: The Architecture of Public Truth (Berlin: Sternberg Press, 2014)

61 Thomas Keenan, 'Getting the Dead to Tell Me what Happened: Justice, Prosopopoeia, and Forensic Afterlives', in Forensic Architecture, ed., Forensis, 35-55.

${ }^{62}$ ibid., 38. 
ignore a basic ground-truth, which led to a person's conviction and imprisonment: composites should not be used in isolation. They can be very valuable, but their contingent nature requires us to be alert to their very real limits, both at the point of their construction and then how they might be understood later. As Frowd reminds us, their legibility is not stable:

‘... human observers make errors when constructing composites and making judgments based on identity...the likeness of a composite to a defendant is related to whether (participants acting as) jurors believe the defendant to be guilty or not, suggesting that composites may not provide independent evidence and that their use in court is questionable. 63

Where the safety and security industries are concerned (global conflict providing a justifiable if double-edged cause for real concern), the project to tame and control the fugitive face has extended to producing faces from DNA trace evidence, an endeavour in fact anticipated by artist Heather Dewey-Hagborg with her project Stranger Visions. ${ }^{64}$ More recently, scientists have reported success in deriving almost-identical facial images from the brain activity of macaque monkeys from those previously shown to the monkeys. As researcher Doris Tsao commented, 'A face is impossible to describe in words... One can imagine applications in forensics where one could reconstruct the face of a criminal by analysing a witness's brain activity ... you could imagine reading out what face a person is imagining. ${ }^{65}$

Forensic art, I suggest, produces prosopopoeial objects in a very literal sense, and in the hands of visual artists, we see how these methods may perform counter-forensic roles. ${ }^{66}$ Attending to the

\footnotetext{
${ }^{63}$ Frowd, 'Facial Composites' 2015: 46, my emphasis. ${ }^{64}$ P. Claes, D. K. Liberton, K. Daniels, K. M. Rosana, E. E. Quillen et al., 'Modeling 3D Facial Shape from DNA', PLoS Genetics 10.3 (2014): e1004224. doi:10.1371/journal.pgen.1004224; H. Dewey-Hagborg, Stranger Visions http://deweyhagborg.com/projects/stranger-visions ${ }^{65}$ L. Chang and D. Tsao 'The Code for Facial Identity in the Primate Brain', Cell 169(6) 2017: 1013-1028.e14. Cited in H. Devlin, 'Scientists discover how the brain recognises faces - by reading monkey's minds', The Guardian, 1 June 2017. Online https://www.theguardian.com/science/2017/jun/01/scientists-discover-how-the-brain-recognisesfaces-by-reading-monkeys-minds [Accessed 5 June 2017]

66 Thomas Keenan, 'Counter-forensics and Photography’, Grey Room 55 (2014): 58-77, taking up Allan Sekula's phrase in the context of ordinary citizens taking on role that state representatives have abnegated, such as legal identification and serving justice, in order to
} 
human face in all its complexity, not just as an indexical likeness which is expected to do particular kinds of work, but also as an icon or emblem of individual personhood onto which we project various fears and desires, forensic art produces culturally complex objects that are in excess of its forensic imperative, crafting 'subjects' in very particular ways that are, in turn, embodied in images which possess a certain performative agency. Acting as our focalizing lens, the composite sketch also serves to illustrate that all forensic art represents a compositing process: we create faces from a range of data that is observed, heard, read, and gathered through material interaction and touch. It represents a similar hybrid practice of producing knowledge through both haptic- and optic-based observation that Joanna Sofaer (Touching the Body) describes in her bioarchaeological work. ${ }^{67}$ Further, these visual depictions open up conversations between artist, witness and community. In facilitating the transfer of valuable information from one context to another in the interests of social cohesion and justice, they arguably represent a particular genre of community art.

Critical interdisciplinary practices question received knowledge - how it is made and how it is used - in very particular ways. Any considering of the applications of science entails a consideration of its dual-use potential and by extension, its political implications. As such, it represents a specific intersection of art, science and legal agency, placing specific demands on how we understand - and practice - the relationship between ethics and aesthetics. In its work with the living and the dead, attending to vulnerable people subjected to the worst aspects of human behaviour - neglect, exploitation, violence and death - forensic art troubles, in critical and productive ways, the illusion of empirical distance that is so much part of the construction of the scientific gaze.

identify individuals and events that have been willfully and violently anonymized or otherwise silenced by the state or its operatives.

${ }^{67}$ J. Sofaer, 'Touching the Body: The Living and the Dead in Osteaoarchaeology and the Performance Art of Marina Abramović', Norwegian Archaeological Review, iFirst (2012): 1-16; and see ead., The Body as Material Culture: A Theoretical Osteology (Cambridge: Cambridge University Press, 2006). 